\title{
Renal Oncocytoma: A Tertiary Care Centre Experience
}

\author{
Authors \\ Vaibhav Vikas, Shanky Singh, Priyabrat Das, Jatin Soni \\ Government Medical College, Thiruvananthapuram, Kerala, India
}

\begin{abstract}
Background: Renal oncocytomas are most common benign tumours with incidence of 3-7 \% of all solid renal tumors. It is often asymptomatic detected incidentally on radiological imaging. Imaging cannot differentiate between oncocytoma and renal cell carcinoma. Histopathology is the only confirmative test. Partial nephrectomy is the treatment of choice. Radical nephrectomy should be considered in cases not amenable to nephron sparing surgery. In this study we studied total of 18 patients of oncocytomas out of 367 nephrectomies for renal masses over a period of 3 years. Incidence rate was $4.90 \%$.

Keywords: Oncocytoma, Central stellate scar, partial nephrectomy, radical nephrectomy, nephron sparing surgery.
\end{abstract}

\section{Introduction}

Renal oncocytoma is a rare benign tumor accounting for $3-7 \%$ of all solid renal masses ${ }^{[1]}$. It is part of a heterogeneous group of large epithelial cell tumors ${ }^{[2]}$. It is found more in males than females with mean age of presentation in 6-7th decade. Oncocytomas mostly are single and unilateral; 4-5\% may be bilateral and $13 \%$ may be multifocal ${ }^{[3]}$. Most oftenly, oncocytoma is an incidental finding in imaging studies or may present as postoperative histology finding ${ }^{[4]}$. It may be difficult on imaging studies to differentiate oncocytoma from some variants of renal cell carcinoma. We present in our study, a series of 18 cases of oncocytoma over a time period of 3 years at a tertiary care health centre in South India.

\section{Material and Methods}

This is retrospective study done from January 2012 to December 2014 at a tertiary care centre in South
India. After taking informed consent, preoperative detailed records including history and imaging techniques and postoperative histopathology reports of all patients who underwent partial or radical nephrectomy were recorded. Patients with histopathology as oncocytoma were enrolled in the study. These patients were followed for a period of 2 years. 2 patients lost to follow up.

\section{Inclusion Criteria}

- All patients of nephrectomy whose histopathology proved to be oncocytoma.

- Patients of all age groups.

\section{Exclusion Criteria: Nil}

\section{Results}

The mean age of patients was 50.5 (range 20-70 years). 18 cases of oncocytoma were detected out of 367 patients of nephrectomies operated over a period of 3 years. Out of 367 patients, 212 underwent radical and 155 underwent partial 
nephrectomy. Incidence rate of oncocytoma in our study was $4.90 \%$ (18/367).

$13 / 18$ patients presented with incidental detection in imaging done due to other reasons and 5 presented with flank pain. None of the 18 patients had hematuria. 12 patients had partial and 6 had radical nephrectomies. 2 patients lost to follow up. Rest 16 patients were followed for a period of 2 years and are doing well.

\section{Discussion}

Renal oncocytoma was first described by Zipple in $1942^{[2]}$. They account for 3-7 \% of all solid renal masses ${ }^{[1]}$. It is found mainly in 6th decade of life with male to female ratio of $2: 1^{[6]}$.

Histopathologically it is composed of uniform, round or polygonal cells called as oncocytes with granular eosinophilic cytoplasm ${ }^{[5]}$. Oncocytomas present usually as asymptomatic mass during imaging for some other abnormalities. Oncocytomas are mostly single and unilateral although $4-5 \%$ may be bilateral and $13 \%$ multifocal $^{[3]}$. Cases of metastatic disease have been reported, yet these are considered exceptionally rare and may represent cases of malignant degeneration or pseudometastases.

Ultrasonography reveals a well-circumscribed unencapsulated solid renal cortical hypoechogenic mass. Some oncocytomas may be isoechogenic or hyperechogenic compared to adjacent renal parenchyma $^{[7],[8]}$. CT may demonstrate a solid homogeneous lesion with a centrally located scar and spoke wheel vascular pattern on arteriography ${ }^{[9],[10]}$. Eiss et al. ${ }^{[11]}$ have described three major groups of non-multiple renal oncocytoma based on Ct findings: (a) oncocytoma $(>3 \mathrm{~cm})$ seat of the classic "central stellar scar", (b) large renal oncocytoma with or without "stellar central scar", (c) homogeneous or heterogeneous with calcifications, (d) small oncocytoma $(<3 \mathrm{~cm})$ with chromophobe cell carcinoma as its differential diagnosis. on MRI, the central scar has a low signal intensity on T1 and hyperintense on $\mathrm{T} 2$ weighted image due to myxoid component ${ }^{[12]}$. Despite these imaging characteristics, differentiating oncocytoma from renal cell carcinoma at times is impossible, justifying the indication of radical nephrectomy. Immunohistochemical staining may sometimes help in the differentiation of oncocytoma from other renal tumors based on markers like CD10, S100 calcium binding protein $\mathrm{A} 1$ and $\mathrm{CK} 7{ }^{(10-12)}$.

Tumors less than $4 \mathrm{~cm}$ in size located at upper or lower poles can be treated by partial nephrectomy. All other patients require a radical nephrectomy. Frozen section analysis is usually not sensitive enough to differentiate the eosinophilic appearance of oncocytomas from eosinophilic RCC and should not be used to guide surgical strategy. Thermal ablation, although sometimes reported as a treatment option, commits the patient to long-term radiographic surveillance, given the lower success rates of these procedures and the unknown longterm outcomes, tests that would be considered unnecessary should surgical excision be performed. In most cases the treatment options are isolated to observation, particularly for the older or sicker patient, and surgical resection, particularly for the younger healthier patient.

\section{Conclusion}

Renal oncocytoma should be considered as differential diagnosis of renal tumors. Radiological features although may assist but do not confirm the diagnosis of oncocytoma. Histopathology is the only modality which can confirm the diagnosis. Partial nephrectomy is considered the most appropriate treatment for the majority of patients with oncocytomas.

\section{References}

1. Lieber M.M., Tomera K.M., Farrow G.M. Renal oncocytoma. J Urol. 1981;125:481485. [PubMed: 7218443]

2. Wang, L.H., Wang, Z.X. and Sun, Y.H. (2008) Preoperative Diagnosis of Renal Oncocytoma: Case Report and Literature Review. Journal of Medical Colleges PLA, 23, 308-312. http://dx.doi.org/10.1_ 016/S1000-1948(08)60058-1 
3. Romis L., Cindolo L., Patard J.J., Messina G., Altieri V., Salomon L. Frequency, clinical presentation and evolution of renal oncocytomas: multicentric experience from a European database. Eur Urol. 2004;45:5357. discussion 57. [PubMed: 14667516]

4. Lieber, M.M. (1993) Renal Oncocytoma. Urologic Clinics of North America, 20, 355359.

5. Alamara C, Karapanagiotou EM, Tourkantonis I, Xyla V, Maurer CC, Lykourinas M, Pandha $\mathrm{H}$ and Syrigos KN: Renal oncocytoma: A case report and short review of the literature. Eur J Intern Med 19: e67-e69, 2008.

6. Marciano, S., Petit, P., Lechevallier, E., et al. (2001) Renal Onococytic Adenoma. Journal of Radiology, 82, 455-461.

7. Lou, L., Teng, J., Lin, X. and Zhang, H. (2014) Ultrasonographic Features of Renal Oncocytoma with Histopathologic Correlation. Journal of Clinical Ultrasound, 42, 129-133.http://dx.doi.org/10.1002/jcu.22128

8. Glaudon, M., Lefevre, F., Martin, B.A., et al. (1998) Produit de contraste et exploration échographique du rein et de ses vaisseaux. Masson, Paris.

9. Fan YH, Chang YH, Huang WJ, Chung HJ and Chen KK: Renal oncocytoma: Clinical experience of Taipei Veterans General Hospital. J Chin Med Assoc 71: 254-258, 2008.

10. Ciftci AO, Talim B, Senocak ME, Kaymaz F, Cağlar $\mathrm{M}$ and Büyükpamukçu $\mathrm{N}$ : Renal oncocytoma: Diagnostic and therapeutic aspects. J Pediatr Surg 35: 1396-1398, 2000.

11. Eiss, D., Larousserie, F., Mejean, A., Ghouadni, M., Merran, S., Correas, J.M. and Hélénon, O. (2005) Adénome oncocytaire du rein: Redéfinition des critères diagnosticques en tomodensitométrie. Journal of Radiology, 86, 1773- 1782. http://dx.doi.org/10.1016/S0221-0363(05)81521-5.

12. Roy, C., Jeantroux, J., Tétékpor, S. and Lindner, V. (2006) Tumeurs du Rein.
Journal de Radiologie, 87, 1025-1054. http://dx.doi.org/10.1016/S0221-0363(06) 74126-9. 